\title{
Hidrotic ectodermal dysplasia of hair, teeth, and nails: case reports and review
}

\author{
L S Chitty, N Dennis, M Baraitser
}

\begin{abstract}
We report two families with the Witkop "tooth and nail syndrome". This term is a misnomer, as the hair was mildly involved in the original case reports and in the families reported here.

$(\Im$ Med Genet 1996;33:707-710)
\end{abstract}

Key words: Witkop; ectodermal dysplasia.

In 1965, Witkop ${ }^{1}$ described an autosomal dominant dysplasia of the nails with hypodontia, which occurred commonly in the Dutch Mennonites of Canada. This condition differed from hypohidrotic forms of ectodermal dysplasia in that affected persons did not have involvement of ectodermally derived glands (that is, sweating was normal) and the hair, although fine, was normal in distribution. $\mathrm{He}$ called this the "tooth and nail" type of autosomal dominant ectodermal dysplasia.

Since the original communication there have been few reports of other families with clinical features which match Witkop's original description. ${ }^{2}$ Some authors have reported families with a similar phenotype but with minor differences, and other similar families have shown apparently autosomal recessive inheritance. There are marked similarities between these families, and it may be that many of the dominantly inherited hidrotic dysplasias of hair, teeth, and nails could be included in the same group. We have reviewed these reports, ${ }^{1-17}$ and describe two additional families, one which has classical "tooth and nail" or "Witkop" ectodermal dysplasia, and another with minor differences.
Family 1
II

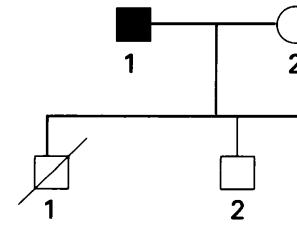

III

2
Dr Chitty.

Received for publication 4 December 1995

Revised version accepted for publication

15 February 1996

Health, 30 Guilford

1EH, UK

$M$ Baraitser

Genetics Clinic Hospital, Tremona Road, Southampton

09 4XY, UK
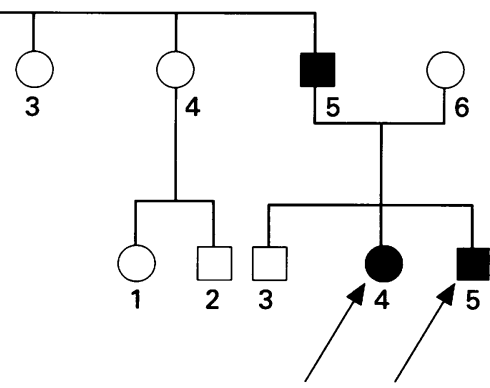

Figure 1 Pedigree of family 1.

\section{Case reports}

FAMILY 1 (FIG 1)

This family was referred to the genetics clinic because two of the three children had abnormal hair and nails. The oldest, a girl (III.4), had fair, sparse, fine scalp hair which was very slow growing (fig 2 ). She had a complete set of deciduous teeth which had a conical crown form (fig 3). An orthopantomogram performed at the age of 4 years showed that there was an incomplete permanent dentition developing, with only two conical crowned upper central incisors and three lower premolars. Her nails were discoloured and were said to have been very small at birth. They had improved with age but were still dysplastic (fig 4 ), the toe nails being more severely affected. Her skin was dry, but she did not give a history of heat intolerance or problems associated with lack of sweating.

Her younger brother (III.5) was born with a cleft palate, which had been repaired by the time we saw him at the age of 2 years. He had had the same discolouration of his nails at birth, but this had improved, leaving him with small dysplastic nails on both hands and feet. His toe nails had never been cut. His hair was sparse, fair, fine, and so slow growing that it had not needed cutting. He had an incomplete deciduous dentition, and both central incisors had conical crowns. His skin was dry but he had no problems relating to sweating.

Their father (II.5) had a complete permanent dentition, but all his teeth were widely spaced and the lateral incisors had tapered crowns (fig 5). He had thick scalp hair which grew well, and nails which, to his knowledge, had always been normal and grew well. His father (I.1) was said to have small teeth, with some missing. His mother (II.6) and older brother (III.3) had complete sets of normal teeth and no abnormality of the hair or nails. III. 3 had a vascular naevus over his right arm with mild hypertrophy, and was thought to have Klippel-Trenaunay-Weber syndrome

FAMILY 2 (FIG 6)

This family was referred for genetic counselling after the birth of the second child (IV.2), who, as well as having the features of an ectodermal dysplasia, had a terminal transverse defect compatible with an amniotic band constriction.

Only the mother (III.9) and her two children (IV.1 and IV.2) were examined. The children's hair was fine and straight, but not sparse (fig 7). There was some scaling of the scalp and their eyebrows were very sparse or absent. Their teeth were small, with increased gaps in 
both primary and secondary dentition, most noticeable in the lower incisors. Their nails were small and spoon shaped (fig $8 \mathrm{C}$ ). They did not report any problems relating to sweating. Their mother (III.9) had widely spaced dentition (fig 9) and dysplasic nails (fig 8A, B). Other affected members were identified by III. 9 because of their sparse eyebrows. Premature balding was reported in affected adult males. Hair microscopy showed hypopigmentation but no structural abnormality in III.2, and trichorrhexis in III.1. Those affected had

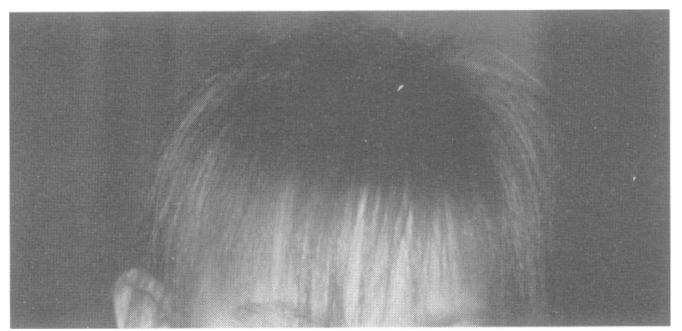

Figure 2 Family 1, III.4, showing the sparse, fine scalp hair. (Photographs reproduced with consent.)

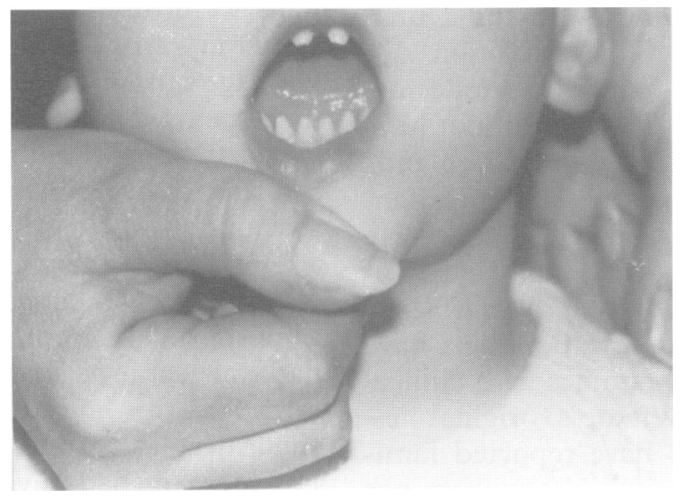

Figure 3 Family 1, III.4, showing the conical shaped deciduous dentition.

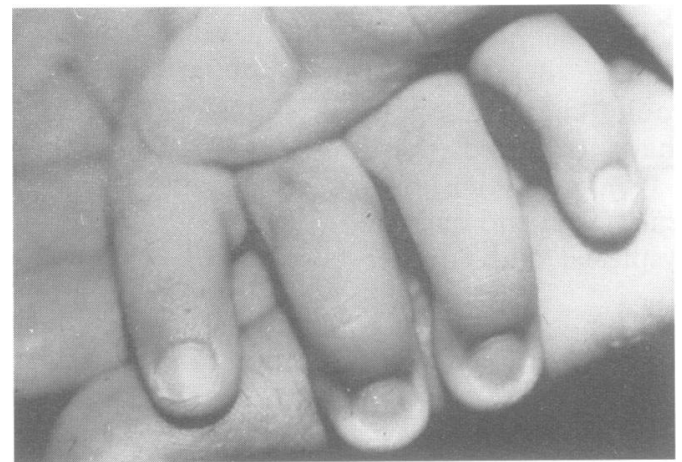

Figure 4 Family 1, III.4, showing the small finger nails.

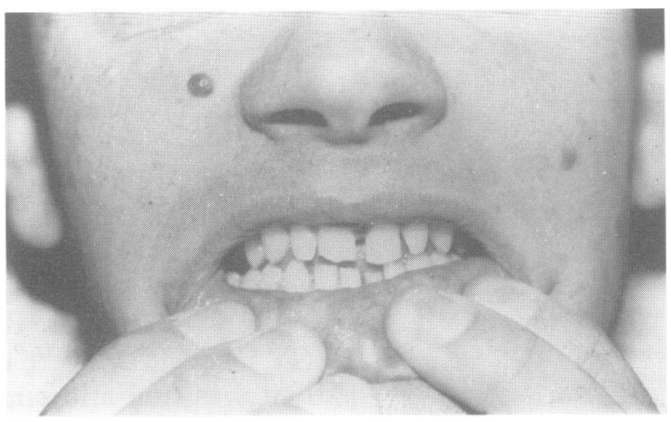

Figure 5 Family 1, II.5, showing tapering of the crowns and widely spaced teeth, the only manifestation of ectodermal dysplasia in this patient. dry skin with follicular papules, particularly on the extensor surfaces of the limbs (fig 8B).

\section{Review of the clinical features in "tooth and nail" ectodermal dysplasia \\ TEETH}

A variable degree of hypodontia of the permanent dentition is present. Adontia is rare in this disorder but has been reported. ${ }^{11}$ Teeth may be widely spaced and conical or peg shaped (figs 5 and 9). There are some reports of congenitally absent deciduous teeth which may also be conical (fig 3). There is considerable variability in expression, and hypodontia is not an invariable feature. The father of the patient described by Weech ${ }^{17}$ (case 2) had "deficient hair and one tooth was imperfectly developed". In the first family reported here there were two affected children, both with peg shaped deciduous teeth, dysplastic nails, and fine hair. Their father had no evidence or history of dysplastic nails or poor hair growth. However, he had conically shaped crowns and was therefore thought to be a gene carrier. There are other published examples showing the wide variability in expression of this condition, with some presumed gene carriers having a few (fewer than five) absent teeth as their main manifestation, ${ }^{11}$ although supernumerary teeth ${ }^{11}$ have also been reported.

NAILS

The nails are described as small and dysplastic and may be spoon shaped or concave. In one report there was longitudinal grooving. ${ }^{11}$ Nails are often slow growing, and the toe nails are usually more severely affected. Some children may be born without toe nails, which subsequently develop slowly but do not usually appear well formed until the second or third decade of life. In the first family reported here, both children were born with small, discoloured, dysplastic nails which gradually improved. The nail dystrophy shows considerable variation in gene carriers: in some there is no evidence of nail dystrophy, whereas in others only the toe nails are affected and to a very variable extent. Still others have severe changes in both finger and toe nails.

HAIR

The hair has a normal distribution, but may be fine (figs 2 and 7 ), slow growing, and sparse. Total alopecia has not been described. In the cases reported by Giansanti et al ${ }^{11}$ the hair was brittle but this has not been a feature in other reports. As with the tooth and nail dystrophy, there is considerable variation in the degree to which the hair is affected, and some gene carriers have apparently normal hair or silky, soft hair. ${ }^{15}$ Other body hair is not usually affected, but there is one case reported with sparse eyelashes and eyebrows ${ }^{10}$ and the second family we report here has virtual absence of the outer one third of the eyebrows (fig 7). Pinheiro et al described a family with features of Witkop's syndrome with, in addition, sparse eyebrows and lashes and mild palmoplantar keratosis. Thus it may be that abnormalities of eyebrows and lashes are variable features in this syndrome. 


\section{Family 2}

।

II

III

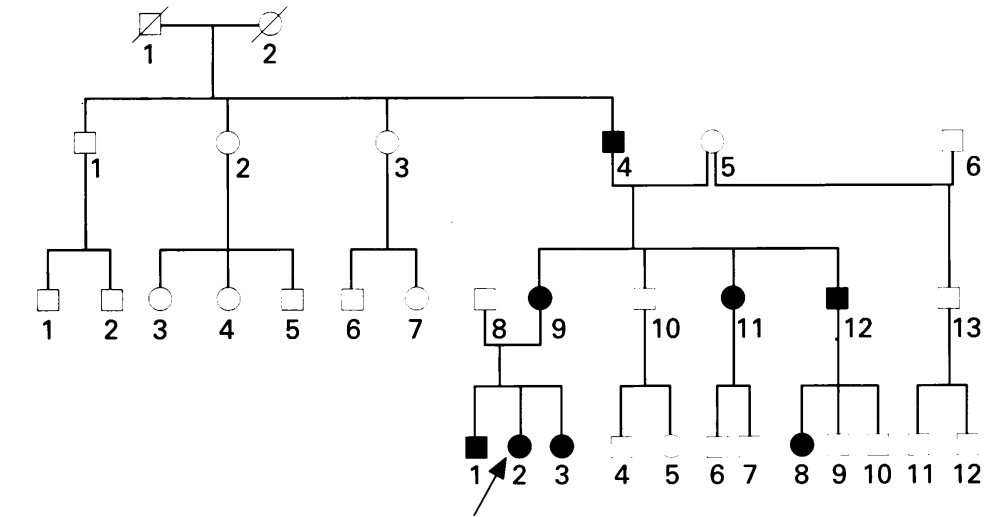

Figure 6 Pedigree of family 2.
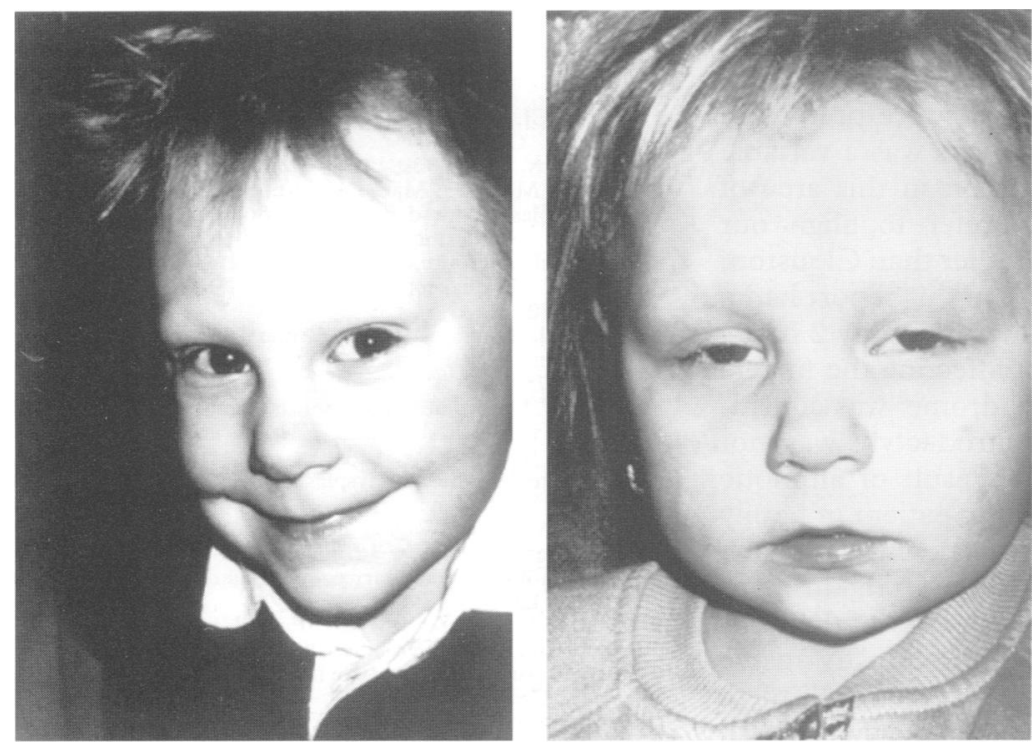

Figure 7 Family 2, (left) IV.1 and (right) IV.2. Note the fine hair and virtually absent eyebrows.
CRANIOFACIAL

There does not appear to be a consistent facial phenotype. The most commonly reported features are a prominent or everted lower lip, a small jaw, and maxillary hypoplasia. One of the patients reported here (III.5, family 1) had a cleft palate.

SKIN

Most affected subjects have normal skin, but some (including family 1 reported here) have dry skin. Slight keratosis pilaris on the arms and legs was reported in a single case in a family reported by Hudson and Witkop. ${ }^{12}$ None of the patients reported gave a history of heat intolerance or problems owing to lack of sweating.

\section{Inheritance}

Inheritance is autosomal dominant, but there may be considerable variation in expression. Very careful examination of relatives of affected subjects must be performed before advising on carrier status, as gene carriers may have minimal signs.

\section{Differential diagnosis}

Differentiation from other types of ectodermal dysplasias is difficult and might not be possible until molecular markers are available. The syndrome first described by Clouston ${ }^{8}$ in 1929 is similar to that of Witkop. Sweating is normal, the hair is fine, depigmented, and sparse and the nails are dystrophic and remain so. There is argument about the involvement of the teeth in this condition, and although oligo- and anodontia do occasionally occur, it is primarily a condition involving hair and nails. Palmoplantar dyskeratosis (sometimes involving flexure areas elsewhere) is frequent in Clouston syndrome and the absence thereof and the
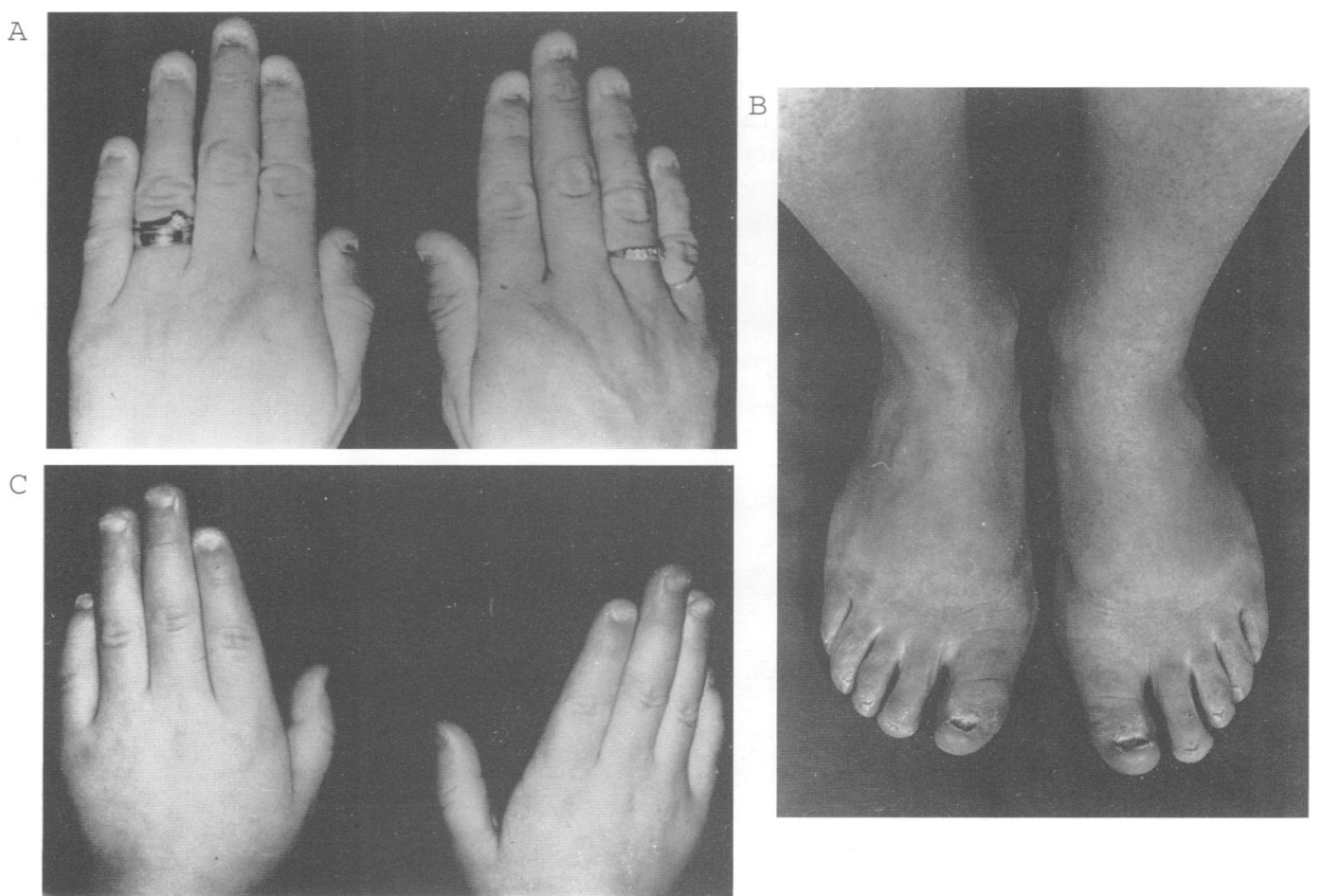

Figure 8 Family 2. (A) III.9 showing dysplastic finger nails. (B) III.9 showing dysplastic toe nails. (C) IV.1 showing dysplastic finger nails. 


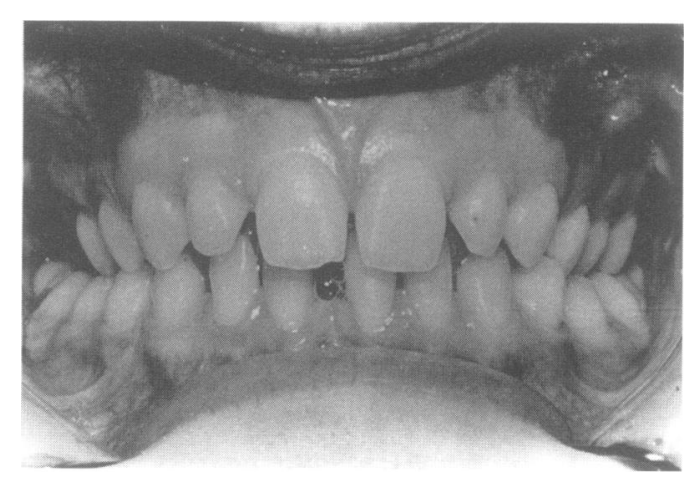

Figure 9 Family 2. Teeth of III.9 showing the increased gaps.

prominence of the tooth involvement in our patients suggest a separate designation. Turnpenny et $a l^{16}$ discuss a four generation family with features similar to Clouston syndrome and speculate about the possibility that it is allelic with it. Their family is similar to ours, but differs in that natal teeth were present in some, and acanthosis nigricans was a variable feature. Such is the confusion in this area of dysmorphology that we prefer to align our family more with Witkop rather than Clouston.

One member in family 1 in this report had a cleft palate and one member in family 2 had a terminal transverse defect affecting the fingers of one hand. The EEC syndrome ${ }^{5}$ was considered in both, but true ectrodactyly was not present (it looked like the result of amniotic bands), and the clefting in the patient in family 2 was confined to the palate, and only one member was affected. Rapp-Hodgkin syndrome ${ }^{9}$ was also considered in view of the cleft, but in that condition the hair is mostly sparse and friable and histologically shows pilli torti. Tear duct function seemed normal in all subjects.

Fried $^{10}$ reported two cousins in a consanguineous pedigree with clinical signs compatible with the tooth and nail syndrome, but as none of the intervening relatives was affected, he considered the inheritance to be autosomal recessive. Other reported cases have other lesions not found in tooth and nail syndrome . A central incisor was reported in the family of Buntinx and Baraitser. ${ }^{4}$ In the family reported by Lowry et $a l^{13}$ a sensorineural deafness seemed to be segregating with the ectodermal dysplasia. The variety of features seen in these cases is such that the condition is likely to be heterogeneous, and an accurate classification must await the mapping of the genes responsible. The majority of these conditions are inherited in an autosomal dominant fashion, with extremely variable penetrance, and great care must therefore be taken when offering genetic counselling in apparently isolated cases.

\section{Summary}

Witkop's syndrome, or tooth and nail syndrome, is an autosomal dominant condition with hypodontia and teeth with conical crowns, with a nail dysplasia which is present from birth and improves with age. The toe nails are more severely affected. Scalp hair may be fine and sparse. Sweating is normal. Other similar conditions may be allelic or may represent mutations at other loci.

1 Witkop CJ. Genetic diseases of the oral cavity. In: Tiecke RW, ed. Oral pathology. New York: McGraw-Hill Book Company, 1965:786-843.

2 Pinheiro M, Freire-Maia DV, Miranda E, et al. Trichodermodysplasia with dental alterations: an apparently new genetic ectodermal dysplasia of the tricho-odontoonychial subgroup. Clin Genet 1986;29:332-6.

3 Brain RT. Familial ectodermal defect. Proc R Soc Med 1937; 31:69-70.

4 Buntinx I, Baraitser M. A single maxillary incisor as a manifestation of an ectodermal dysplasia. $f$ Med Genet 1990;27:648-51.

5 Buss PW. Syndrome of the month. Cleft hand/foot: clinical and developmental aspects. $\mathcal{F}$ Med Genet 1994;31:726-30. 6 Carabok JI, Pigott KLM. A case of partial anodontia, with associated ectodermal dysplasia. Br Dent f 1956;100:31112.

7 Cohen MM Sr, Wagner R. Ectodermal dysplasia with partial anodontia. Am $\mathcal{F}$ Dis Child 1944;68:333-4.

8 Clouston HR. A hereditary ectodermal dystrophy. Can Med Assoc $\mathcal{F}$ 1929;21:18-31.

9 Felding IB, Bjorklund LJ. Rapp-Hodgkin ectodermal

dysplasia. Pediatr Dermatol $1990 ; 7: 126-31$.
10 Fried K. Autosomal recessive hidrotic ectodermal dysplasia. fMed Genet 1977;14:137-9.

11 Giansanti JS, Long SM, Rankin JL. The "tooth and nail" type of autosomal dominant ectodermal dysplasia. Oral Surg 1974;37:576-82.

12 Hudson CD, Witkop CJ. Autosomal dominant hypodontia with nail dysgenesis. Report of twenty-nine cases in six families. Oral Surg 1975;39:409-23.

13 Lowry RB, Robinson GC, Miller JR. Hereditary ectodermal dysplasia: symptoms, inheritance patterns, differential diagnosis, management. Clin Pediatr 1966;5:396-402.

14 Pinheiro M, Gomes-de-Sa-Filho FP, Freire-Maia N. New cases of dermoodontodysplasia? Am $\mathcal{f}$ Med Genet 1990; 36:161-6.

15 Redpath TH, Winter GB. Autosomal dominant ectodermal dysplasia with significant dental defects. Br Dental f 1969; 126:123-7.

16 Turnpenny PD, De Silva DC, Gregory DW, Gray ES, Dean JCS. A four generation hidrotic ectodermal dysplasia family: an allelic variant of Clouston syndrome. Clin ly: an allelic variant of
Dysmorphol 1995;4:324-33.

17 Weech AA. Hereditary ectodermal dysplasia (congenital ectodermal defect). Am $\mathcal{F}$ Dis Child 1929;37:766-90. 